\title{
Sangha: Collaborative Improvisations on Community
}

\section{Vijay lyer}

Saxophonist Rudresh Mahanthappa and I have been collaborating constantly for nearly a decade. In 1995 Steve Coleman introduced us to each other; Coleman had me in his band the time and had given Rudresh some lessons. We both immediately knew that this would be an important connection; we were two South Asian Americans of the same age (born in 1971), trying to gain a foothold in the world of creative improvised music, and trying to address issues of identity, community, and history through our work, while negotiating the pitfalls of pigeonholing and selfexoticization. Our many collaborations - as the duo Raw Materials, in the Manodharma Trio with South Indian percussionist Trichy Sankaran, in each other's quartets, and in other ensemble formats-have provided a crucial space for our ongoing creative inquiry, as improvisors sitting at a particular intersection of composite realities. In our recent years working together out of New York City, increasingly frequent interactions with the mainstream have brought a pragmatic frankness to our thinking about these issues.

Sangha is a Sanskrit word for community (as well as the name of a suite of music that we co-created for our duo). What follows is an edited transcript of a conversation we had on July 25, 2005, at Dimple, a restaurant on $30^{\text {th }}$ Street in Manhattan.

\section{So, Rudresh, maybe you could tell me a bit about how you got into improvisation and what your path was to get to this area of music.}

Well, I started to play saxophone in elementary school. I had a very creative teacher, and I kind of started listening to instrumental R\&B and soul, like David Sanborn and Grover Washington. I eventually got to Charlie Parker, and I was clear on the fact that that was improvised music, in this way I could kind of get my head around as a high school student. Not necessarily the complexities, but at least I could tell the difference between the melody and the improvisation! But at the same time, my parents were listening to some Indian music, and I knew that that was also an improvised art form, but didn't necessarily understand structurally how all that was put together. But jazz really spoke to me.

\section{Why is that?}

With Bird, there was such fire, and urgency, and virtuosity, and joy-all these emotions wrapped up into this one voice that was just so charismatic for me. I just wanted to be Bird! At least for a while. It was funny, that Clint Eastwood Bird movie was on TV the other day, and I realized that I hadn't seen it since it was out in the theater. It was so funny to watch it now as opposed to watching it then, not having seen it at all in between. Because when I saw it then, it was like, This was the guy I want to be. 
That came out when we were in high school, right? In the mid-'80s?

I think it was our first year of college, actually. Fall of ' 88.

That was around the same time that Straight, No Chaser came out.

Yeah, I think Straight, No Chaser came out about a year later.

Because I had the same experience, basically, with that movie.

Yeah, it's really interesting... you know, and obviously there were all these issues with [Bird], because historically it was inaccurate, and the way it painted Charlie Parker was quite questionable in a lot of ways. But it was interesting to watch it the other day because I kind of got a little bit in touch with why I got into this music, what about it inspired me then, and also what about it inspires me now.

\section{Improvised Immigrant Communities}

So what was it like, being who you were at the time, and being into something like that?

It was a complete anomaly on so many levels. First of all, hardly anybody was listening to that kind of music at my age. Also, I was dealing with the fact that even in $9^{\text {th }}$ grade I knew that this was what I wanted to do. "Make a living" is a funny way of putting it, but this is what I wanted to dedicate my life to. But I didn't really say that to anyone for years, because it was so taboo. In Indian-American immigrant culture, you know- "We didn't come to this country so that you could become a musician!" That was never something my parents said, but they didn't have to say it; it was kind of implicit. It was a lot to deal with, actually.

People always point to the role of musicians in society in India-I feel it's actually true all over the world. Musicians are generally second-class citizens, or worse. When I was on the road with Wadada Leo Smith, he was telling me one horror story after the next about life on the road, or being swindled, or whatever. And finally he said, "You know what, Vijay? I think that jazz musicians are some of the most hated people on the planet." (laughter) So you know, it's not just reserved for nagaswaram players or something like that.

Right.

I think it relates to the role of the griot, these people who have this knowledge that is so crucial to the way that everyday life operates, and particularly to the way ritual functions in life, but because it's so crucial it's almost like they're not really allowed to participate in everyday life. It's sort of like you're cursed with this knowledge or something. 
I always wondered with my parents, when they were "anti," where did the line get drawn between "You're not supposed to do this for a living" and "Hey, I want to take you to this concert this weekend"? So we're paying money to see this person whose artistry we respect, but where does that break happen? It comes down to worry, when it's a parental thing. Parents don't want their kids to starve. And I think that was more the case with my parents. But definitely there are family situations you see where it's like, "You're not going to be a musician because that's just up a level from a beggar."

Right. Also, I came to realize that there was something quintessentially western, and even American, about this myth of self-actualization - the idea that you would find your true calling, and it would be what you love to do, and what you're great at doing, and that would be where you belong in the world. That sort of picture really presupposes a lot of social freedom and mobility that people in the culture of our ancestors didn't generally have. Their lives were bound by familial obligations and duties, and social stratification that went hand-in-hand with what your career choice was.

Absolutely.

I think that self-actualization bug was something we all got bitten by, having grown up here. But it was so alien to my parents, really, the idea that you would actually do what you want. Who cares what you want? It's not about you!

Definitely. Or the idea of being on a "mission," or-not to be too highfaluting, but having some kind of greater calling, or hoping to make some difference in the world...

To have an effect on people outside of your immediate family. But at the same time, it's true for my parents, and I think certainly for your father as well, that they also sought out new opportunities that lay beyond the immediate horizons. That's why they all came here. So they did have a certain amount of agency, or a certain critical perspective.

Breaking the norm, yeah. But I think we did a good job of pushing those limits even further!

My sister and I both talk about that — as she's emailing me from Cameroon, where she lives by herself...!

Wow. Well, when my parents came to terms with the fact that this was the thing to do, my dad, being a college professor, wanted to make sure I did it right. So, his plan of action was to go talking to a bunch of people and find out where the best places to study jazz were on a collegiate level, and find out what the application process was like. Which I'm definitely grateful for. I didn't know what I was going to do. I wasn't about to move to New York when I was 16 and just rough it or something.

Though it has been done. 
It certainly has been. But in my case, that would not have been good for anybody involved. (laughter) And then I ended up at UNT, formerly known as North Texas State. And that was very strange because that wasn't what l'd imagined studying jazz was going to be like. It was kind of like joining the military; it was more about acquiring a skill set than about actually creating something. It's like a trade school for jazz. That was very disappointing, and I definitely had to get out of there.

Not only that, but I was definitely also coming to terms, or getting in better touch, with my cultural identity. I think the biggest thing that hit me about going to North Texas was, more than with the white community [in Boulder] that I grew up in, was this overwhelming sense that I was not white. Not that I thought I was white, but I guess I thought I could hang with white.

Right, like maybe growing up in suburbia it doesn't feel like as much of an issue until you really have to start making life choices.

Right, definitely. And also, Boulder was a very educated college town, and there wasn't a lot of overt racism. But Texas - that's the South. So, there were two issues there. One was that I didn't really have any other Indian American friends, people with the same kind of story that I could talk to. And I was also very overwhelmed by the fact that I was enrolled in this jazz program that had very, very few African American students. I mean, you could count them on one hand. There were so many things wrong with that picture, in addition to the basic education that I was getting, that I bailed.

And Berklee College of Music in Boston was much more balanced. It was balanced racially and Boston was a big city. At least the numbers were balanced. There was no sense of racial unity by any means, but at least there were all these different cultures there.

It sounds to me like maybe in Rochester you were part of an Indian community.

Yeah. It's still true that pretty much all my parents' friends are Indian. They're from all different ethnic groups in India. It's built steadily over the time that they've been there, which is over thirty years. They were among the first handful of Indian families there in the early-mid 70s. They were all pioneers, I guess you could say - improvising their way through upstate New York.

Yeah, and improvising how to raise a family in this culture.

Yeah, every single choice that a non-immigrant family could take for granted really had to be thought through. My parents didn't know what public school in the US was like at all, you know. They did their best to move to a school district that was well-ranked, but they didn't really know what they were getting into. I owe a lot to my mother for really trying to be involved in how I was being educated. Sometimes maybe getting too involved! But it was out of concern - fear of the unknown, essentially. 
And also, I think, it's also that striver's mentality that anybody who survives in India necessarily has to have. I think when a lot of immigrant families come here from South Asia, they already know that the system doesn't work - because it doesn't work for them there either.

The assumption is that the system doesn't work.

Yeah. So they come here and say, ok, how can I get my stuff working, for myself and my family? No one here is going to help me, so I have to help myself.

(laughing) Which is definitely a model that we've had to use for ourselves. It still is like that.

Well, we have had some help, but we had to work around plenty of obstacles. But it's a sad thing, in a way. What's also sad is that there's something in there that resonates with a certain American myth about the self-made man, and rugged individualism, and all this kind of stuff. Part of what makes it successful is that it's so cold-blooded; because supposedly nobody cares about you, you don't have to care about anyone else. It's funny because that's not really the way that this country was intended to be. America still sees itself as a Christian nation, but that's not a very Christian ethic. It's the opposite of "Love thy Neighbor." It's more like "Screw thy neighbor."

But I think that for people whose first priority has to be survival, it's an issue, in a way that it isn't for people who've been in this country for generations - in particular, the well-to-do who've inherited wealth for generations. That's not something that they think about. So the life choices that they make... "I think I'll be an artist." "I think I'll take my kid to music lessons." You know, just these basic things that couldn't be taken for granted in our case. Lord knows, neither my parents nor yours knew what they were getting into when they started us up on our respective violin and recorder!

\section{Approaching Traditions}

Anyway, maybe you could talk a little about how in more recent years you've come to deal with aspects of Indian music. Or failed to, or avoided, or embraced...

Yeah, God, what a roller coaster it's been!

I think for both of us. We've been in on it together for nearly a decade now.

Absolutely. Being Indian American and playing jazz, say more than 10 years ago-not often, but often enough to get under my skin, I was asked, "Do you listen to Indian music? Do you use any ragas?" And I felt like I was so confused as to how to explore Indian music on my own terms and at my own pace, and just in a way that made sense to me, being 
Indian American and already having a strong foundation in jazz. I didn't quite know how to go about it. And also, at that point, if I was going to deal with it, how to feel like I wasn't doing it just for the sake of doing it, or just doing it blatantly in this kind of emblematic, superficial way.

I think what made a big difference was going to India in '94 to play at the JazzYatra festival, with this band from Berklee that was primarily Indians, actually. I got to see some great concerts there, and again just buy CDs and tapes on my own terms - I saw this, I want to get this, I can relate to this, I want to deal with this-as opposed to somebody telling me the good albums to listen to, the good artists to listen to. And also getting a greater sense of what South Indian music is as opposed to North Indian music, beyond just instrumentation or whatever. And so on my first album [Yatra, 1994], I felt like I dealt with some concepts in a very, very elementary, almost hidden way, in a way that was comfortable for me.

It wasn't a put-on, basically. It was just an honest beginning to your journey.

But in the meantime I was talking to this entertainment lawyer, and she was on my case about doing something blatantly Indian, and how she'd be able to sell it, and all that. You know, that kind of tripped me out too. Eventually I did try this experiment with [Pakistani-South American guitarist] Fareed Haque and a tabla player, and it was kind of fun and goofy, but then I definitely put that aside pretty quickly. I feel like I might resurrect that band next year. It's almost ten years later, and now it would mean something completely different to me. It would be for all the right reasons, really in the spirit of collaboration, and really improvising with a greater base of knowledge, as opposed to doing this thing that "seems Indian."

\section{To get over.}

Exactly—though with who, I don't know. "Getting over" means, "You need to pigeonhole yourself further, because you're just a wild card. Here you are, you're Indian American but you're playing jazz, so you don't fit into any preconceived notion of what a jazz musician is supposed to be. It all seems so edgy, if we could put you in a box, that way the people could understand." And I think that situations like that made it clear to both of us that we need to do something to make people understand this thing that we are actually trying to do. It's taken over 10 years for people to be able to actually deal with it as its own thing. The pigeonhole thing is actually waning.

I think it had to do with that time in history - because let's be frank, it was 10 years ago and the world was a different place. I made my first album in '95, you made yours in '94. Actually I did this interview with Paul Olson for Allaboutjazz.com when we were in Chicago [in May 2005], and he quoted the liner notes to Architextures, which I had written in '96 or something. I had said something like, "This album represents my perspective as a member of the South Asian diaspora, but also as a human being with a mind, body, and soul." You know, stuff that really shouldn't have had to be said. It ought not to have been necessary to say that. But frankly, at the time it was necessary - in a way that it maybe it isn't today - to use the opportunity to say, "I am a fact. Look at me as just a fact, as part of reality, not as part of your fantasy or your dreams about The East; just try to deal with me on my terms." 
Of course, that was the sort of thing that prompted Gary Giddins to call me "full of words and himself." But I felt like, either frame the discourse with your own language, or else let them take it over and completely misrepresent you. Looking back, we were both at this point in our careers where we had to make this statement, to say, OK, look, this is not a simple reality that we're dealing with. Please accept it on our terms - it's the least you could do, even if you don't like it.

Or even if it makes you a little uncomfortable.

Right.

What you were saying about the way you were dealing with Indian music is completely parallel and completely contemporaneous with where I was at. I was checking out a lot of these South Indian classical concerts in the Bay Area, mainly in Palo Alto, which had such a strong South Asian population because of the Silicon Valley. They were able to bring over artists from India to perform, so there was a regular concert series and I was going to that twice a month. And that was where I learned a lot about just the basics of listening to Karnatak music. Not that I'm an expert or know anything at all, really, about the details of it, but I know how to participate in that kind of event. That is something you don't get from listening to records - some of those extramusical factors that you can't really get from books or pedagogy, really. You learn a lot from being immersed in this community that's participating in these events.

So that, on top of getting a hold of Trichy Sankaran's recordings and his book, and these kinds of things. Again, just approaching that music on my terms, which is the way I approached jazz actually - whatever my terms were when I was 16 years old.

That's definitely a real thing. I mean, you didn't go to music school, which is interesting to me, because I think in some ways, by not going to music school, you were much more able to develop a personality and a voice than someone who goes to music school. Because, especially at these larger schools, you just feel like you're fighting a system, you know. So if you are trying to do something unique, you can't...

Well, there's pressure to conform, basically.

Yeah. You have like a hundred people who you're supposed to respect, these faculty members who are trying to punch a hole in all of it. It's almost worse. I feel like there were some people who had strong individual voices that maybe just didn't even have the personality type to forge their own thing and just go forth.

It's especially funny when you think about how the people we look up to in the history of this music were only people who did that. There's no one we admire who just participated in some kind of jazz groupthink. (laughter) 


\section{Centers and Peripheries}

So, how has it been since you came to New York, dealing with these issues, particularly being in an area where there's such a substantial young South Asian population, with its own scene, its own buzz, its own activities, and all that?

I still feel like I'm totally on the perimeter of that community. I think that community is well aware of me, but I'm not an active participant. And there are all sorts of reasons for that. I think that community has grown, too, but when I moved to New York [in 1997], the idea of South Asian artists and progressive thinkers was kind of still in the space of getting to know itself. There seemed to be a greater focus on being South Asian than on trying to produce high quality work. And I feel like that's changed a lot, also. I mean everybody grows, obviously.

It was sort of a critical mass question. Maybe in the mid-90s in New York, right before either of us moved here, there was a growing scene of artists who were really interested in representing South Asian-ness in their work, and often in very elementary ways; basically that became the point of their work. And then there was a certain scene, between New York and Toronto and LA, these little pockets of South Asian arts and activism, which would perpetuate a certain sensibility. There were people who made art specifically for that community and that scene, and for nothing else.

It's partially demographics, I suppose; as we both know, we were among the first kids born to this major wave of immigrants from South Asia. So being in our early-mid-30s, we're on the front end of it, but now there's a whole multitude of people out there in their $20 \mathrm{~s}$, who are out there doing stuff on a high level.

Yeah, and there was almost no possibility to do that when we were in our 20s. l'd be interested to see how that's occurring in places that aren't necessarily big cities but that have a larger Indian community. It'd be interesting to check that out.

But I think just being on the periphery of that scene has allowed me to do what I do, in a way. Because to the non-South Asian or non-South Asian American, it just seems from the outside like people in our community are doing all these things that are informed by the culture, but also contemporary. So, because there was this scene emerging when I moved here, even though I wasn't a part of it, it sort of validated what I did-because I was seen as part of that continuum, even if I wasn't directly part of that scene.

That's why that initial community-focused work that people were doing was so crucial. We used to laugh about it, but it was really important to have this "safe space."

Right, even if we never really inhabited it. 
But we actually did. Our first gig together was at one of those safe spaces, right? It was at Desh Pardesh.

Oh, right, that's true.

So it sort of nurtured us as much as it did anybody else.

At the Jazz Standard the other night [an upscale New York club, after a performance by Rudresh's quartet], somebody said that they really loved the music but they couldn't really hear what the Indian influence was. But they said it in kind of an ignorant way, like, "Actually, I'm not that knowledgeable about Indian music." But I realized that it's been a really long time since someone has said that, thankfully. I just feel like we're at this level where we both have to explain less and less, and the music will just be listened to on whatever people perceive its own merits to be. There isn't this preamble that has to come, like, "This is this because... and I am this because... and that is why..."

I think in New York, maybe that can be said. But I think in some of these smaller towns, just seeing my album mentioned in various local newspapers around the country - I get these Google News Alerts - it's still repeatedly said that I'm mixing Indian music and jazz, or I'm playing jazz with an "Indian flavor." That depiction never really gets complicated. And I don't know how long it will take before it ever is. Will it ever be, in terms of this really mainstream discourse?

That's a good question.

The thing is that this is what people expect us to do in the South Asian community as well. But I'm interested in what you were just saying - that you find yourself on the perimeter or fringe, basically an outsider in the current Desi [South Asian diasporic] New York scene. And I see myself the same way. And I'm wondering why that is, and why you think that is.

Yeah, that's a good question. I think there was a long time where I actually felt bad about it, but I decided to stop feeling bad about it a few years ago.

I guess I still have twinges of bad feelings about it, because I find that barriers are maintained in the way that music functions, in all these different cultures and subcultures. I find that what's true in the mainstream superstructure gets transferred even to these little fringe subcultures, like the South Asian underground scene. And in particular, the role that jazz has today, or anything affiliated with or having any relationship to jazz: it's sort of a pariah. It's true what Wadada said; it's the sort of thing that nobody wants to like.

And that continues to be true even in the club culture scene. And what's funny is that if you go to these Desi club nights where there'll be DJ's and people playing tabla and dholek and stuff, the way they promote the events and the way they talk about it afterwards, they're using all this idyllic 
language about improvisation and freestyling. You know the kind: these people are "on some next shit" because they're making it up off the top of their heads. And it just strikes me how that same language is never used by those people to describe what we do.

Yeah. I think when people think of jazz, the younger generation thinks it involves too much homework. Somehow this idea of just going and listening and not trying to understand it is kind of inconceivable. Somehow when jazz comes up, people feel like they always have to have a background, they have to understand it. I was online and I found some blogs about your quartet shows at the Jazz Standard in June. And some singer had posted to her blog, and it was this

whole rant about how she's been trying to get down with modern jazz but she just can't deal with it. And the whole thing was so laden with -it wasn't about the music, really. It was about her feeling like she's supposed to understand this but she can't understand it. And obviously there was this psychological thing happening there, where she was maybe on the verge of feeling ignorant or stupid or something like that. So that's actually seen as a reason for not liking it. I mean, do you feel like when you go to the museum and look at some crazy modern art, do you feel stupid? I generally don't, but I kind of decided a long time ago that I was just going to deal with it on my own terms.

\section{But do you go very often to the museum?}

No, not often, maybe when I'm traveling. But even when we were in Amsterdam, I saw some really bizarre art, and I don't know where it's coming from background-wise, but I thought it was fabulous.

Right, and didn't you want to find out more about it, rather than less?

Definitely.

But it's a funny thing about the way music functions in people's lives, in a way that no other realm of the arts does, which is that first of all, nowadays they tend to be in total control of it - listening to whatever they want, whenever they want. So it becomes this real mood-enhancement device. And also it's something that people experience mostly passively, which brings up the issue of live music in general.

The other thing, though, is that if you ask any average Joe on the street, I bet you they're not going to have real convictions about writers they like, or theater that they like, or painters they like, but they're going to have convictions about the music they like. "I really like this guy." "This song is fucking great." Most everyone is really very opinionated. So that's kind of a funny thing, when you hear two people talking about how great this song is, and as a musician you think, wow, that's a great song, huh?

So jazz just challenges people-just the word "jazz" challenges people in all sorts of bizarre ways. It's really a shame that people can't just come to it with a blank slate and then decide if they like it or hate it, or just be able to groove off the energy or the emotion of it...

Just have an experience, and be present. People bring all these hang-ups to the table. But you know, 
I also think that today things are different, partially because of the hip-hop revolution, which has made black music more mainstream than it's ever been in America. Like, it's so mainstream, that if you're not dealing with it, then there's something wrong with you. Because that wasn't the case when we were coming of age. Hip-hop was this threat from the margins, like jazz once was. Hip-hop wasn't always used to sell...

Everything.

Budweiser, Bud Light. You could call it a revolution, but it's mainly really just a capitalization.

Yeah, it's just business.

But that also kind of contributes to jazz being more marginalized. Because now there is a mainstream black culture, and it's hip-hop. So who do you think you are, dealing with jazz?

Right.

\section{Indian Enough}

When I first moved to New York, I kind of tried to hang out with that [young South Asian American] community, and I felt like there were also a lot of weird political things happening. It was kind of a molehill that people were vying to be the king of, and I just didn't want to have anything to do with that. And I also felt that artistically I was at another place, too. But I think it's kind of funny to see now that more of that community is coming to see what we do. A little bit, at least.

I remember talking to DJ Rekha about this a long time ago, and her thinking was, "You have to get mainstream success before the community will embrace you." And I guess that's maybe what we're seeing now, is that because we get written about in the Times and the Voice and The New Yorker, people are coming around.

But also, I don't go to Basement Bhangra [a long-running monthly South Asian-oriented dance night at SOB's in Manhattan]. I just don't go and hang on the scene. I don't go to these parties. No one calls me to go to these parties either-they did a long time ago, maybe.

Something that we haven't talked about in a long time, probably because we haven't needed to, is that one of the things I experienced at Desh Pardesh and other sorts of events, that I experienced again moving here, is that you have this Indian American community, but you have such varied experiences. There are people that are part of that community who are more on the immigrant side - maybe they were born in South Asia but their family came here when they were teenagers. Or you have me, where my parents came here in the 50 s. 
And also you have all these different ethnic and religious groups, and the North-South thing. There's a growing mainstream within that community that centers around Bollywood films and Bhangra music, and I know that that's not everyone's experience. To use an extreme analogy, it's sort of like centering your experience around Brittany Spears and Tom Cruise. I mean, certainly people must have some sort of critical perspective when it comes to this stuff!

But when people come here there's a certain nostalgia for it. I think people relax their critical guard about it because it's like, Well, I'm here in this foreign country, and the music that I listened to growing up was the stuff that was in movies and on MTV Asia and on the radio, and to see it reactivated here just reminds me of home. Or else, This is the stuff that my parents listened to, and I'm into it because it...

Reminds them of home in a different way.

Right. And I find that even in the "cutting-edge" underground South Asian scene that nostalgia is still at work. People are really interested in reconstructing this imaginary homeland out of these little scraps of culture. You can have a guy playing tabla, but oh, it's urban and modern because there are some banging beats underneath it.

l'll get back to what I was saying before, but you know how we talk about jazz being the pariah? In the same way that people don't want to deal with jazz, there's this younger generation, both in India and definitely in the Indian American community, that just doesn't want to deal with Indian classical music either. And that's one of the things that we've dealt with. So that is to say that that kind of furthers us from the "feels like home" vibe, because that's not home. I mean, most aunties and uncles, they know the names of some of these musicians, but they don't own any albums, you know, they don't put that stuff on.

But what I was going to say is that, when I came to New York, briefly hanging out with that Indian American community, once again I just didn't feel Indian enough. And there's this very specific sort of pit in my stomach that I get when I start feeling not Indian enough. And I started having that all over again, and it made me just not even want to deal. Plus I was in this situation where I felt like I was having to make decisions about, like, going to see some music I really wanted to see, and hanging out with this community that I wasn't even sure I was down with. I wasn't even sure they were down with me.

Or with what you were into.

Exactly. And still...not in a long time, and not in New York, but l've still gotten that, you know, the DJ and the tabla player that plays with them, they're a particular kind of artist, but when I say I play saxophone, they say, "Oh, I used to play clarinet in elementary school." It's like, wait, you don't see me like you see those guys? That kind of took me out.

But I think that one thing we're running into, in terms of this disconnect with the Desi scene, is that 
the music they're dealing with functions in a certain way.

Yeah, it's more about the community gathering, you're right.

Right - and, what they're dealing with is not framed as art music or concert music. Their points of comparison are Bollywood pop songs, rock, hip-hop, and DJ culture. What we do is basically art music; that's just what it is. Jazz has all these roots in vernacular traditions, but in our approach to it, it's concert music. In that sense it has more to do with the classical traditions than it does with pop music, Bollywood, or any of that. So musicians who are engaging with these pop traditions from India are going to connect with these audiences, whose entire experience of music is mainstream pop, be it Indian or western. And then those same audiences will see us and think, Why? What are they fighting for? Why are they trying to challenge me? I already know what music I like.

In a way, it speaks to how you and I grew up, and the kind of perspectives that went along with our upbringing and the time and place that we grew up. Because I think to grow up today in a South Asian American community is very different than it was when we grew up. People who are ten years younger than us have had so many more precedents. For one thing, there's much more of a critical mass. You can go to movie theaters and see Bollywood films. You can rent them by the truckload at your local store. All your friends could be Indian. Not just your parents' friends, but your friends. You can run around in a South Asian hip-hop crew! That sense of alienation that we grew up with, being outsiders looking in at all times - they don't have that. We're sort of relics of this transitional era in America.

I think it's important that we continue to represent that, because in a way that perspective will be forgotten pretty soon. People will not remember that there was a time when it wasn't obvious how to be South Asian American. When every single choice was an adventure, you know, a great leap into the unknown. An improvisation, if you will.

Crazy.

\section{Negotiating Across Communities}

I wonder if you could say a little bit about your relationships with other communities of color, specifically other Asian Americans and also African Americans in this music world.

I haven't really dealt with many other Asian American artists-have I? Can you remember? See, I haven't, outside of the South Asian community. But my history with the African American community is a little bit bizarre. I think pre-New York, you and I had very different experiences. In Chicago, I didn't feel accepted by that community, or valid to that community, until it was very clear that Von Freeman really liked me, being the granddaddy of it all that he is there. I remember going to jam sessions on the South Side of Chicago and being called, you know, college boy, and...definitely 
being made to feel like an outsider. And really being confused by that.

Was it as much a class issue as a race issue?

I don't know, I guess it could have been, but I don't know what would have made it seem like a class issue. I was as destitute as anybody!

Well, "College boy" says something.

That happened once or twice, and I don't even know what actually even encouraged that.

Was it what you were playing, perhaps?

Yeah, right, did it sound collegiate?

Maybe that's what people thought of Bird. There's some quote from Von, in fact, saying that about him: Actually Charlie Parker was a blues musician, but he was playing the University blues. Like, taking it to advanced degree level.

Right.

Well, yeah, it's interesting, for me, it had a lot to do with who I fell in with when I was coming of age. And also, I guess that jazz school experience can be so racialized, and my whole experience was outside of that. And I was really dealing with musicians who had nothing to do with that. In particular, living in Oakland and playing with people on the scene in Oakland, from the Bird Kage [a local club with a weekly jam session] to playing with [legendary drummer] E.W. Wainwright. And then these different crucial connections I made, with Steve Coleman, and George Lewis, and also my connection with the Asian Improv scene. And also, the tools I was provided with in my education at Yale, in terms of critical thinking about race and power. It helped me ground myself as a person of color and really frame what I was doing from that perspective.

Sure, that makes sense. I remember, I'd play with Willie Pickens sometimes, this pianist from Chicago. I definitely got the sense that people would razz him a bit, like, why are you playing with that guy? That guy being me.

Well, that happened to me in Oakland a bit, too. Like there was this young trumpet player who used to hire me until his drummer told him not to hire me. But for me, I guess, it was a while before I even thought that I could play, like, that I could deal on any real professional level. And so I felt like it was a combination of me barely being able to play, and this not really being what I was "educated" in, and whatever, just the fact that I was trying to figure it out, basically. So I guess I chalked up a lot of 
those similar experiences not to race but to musical choices.

But I think probably the Bay Area was different, too. Ever since Sly and the Family Stone, I think the Bay Area has been this kind of integrationist utopia.

Yeah, certainly. Chicago is definitely not that.

Chicago, in the several times that I visited you there and that we went back to play there, has always been really stark to me - more so than anywhere on the east coast.

It's pretty unbelievable how clearly the city is segregated. Yeah, and you just think about the geographical issues. I never had a car in Chicago, so getting to some of these spots on the South Side was just a pain in the ass. So I can almost chalk up my lack of communication with that community to the fact that I didn't have a car!

\section{Do you think those issues are different now?}

I think they're very different. I think the New York manifestation of not knowing what to do with an Indian American jazz musician is actually much more positive. Because I feel like the African American community is down, and for the most part the white community is down...like, everyone is just kinda down. Not that we have the power to bridge this gap, but we are in this funny middle ground, where the white cat that feels uncomfortable calling the black cat doesn't feel uncomfortable calling us, and the black cat who doesn't know who Ben Monder is knows who we are. There's a funny thing that happens there.

And it even manifests when we play. I remember one time we played at Sweet Rhythm [another New York venue], and that woman Elizabeth Baratz I think is her name, [proprietor] James Browne's business partner, was just raving about how diverse the crowd was. It seemed like she'd never seen it that diverse at that club, in the years that it'd been in operation. So that was pretty significant, I thought. Not that she had a damn thing to say about the music! Reminds me of when we used to play at Yoshi's [an Oakland club], and afterwards the owner, Kazunori, would be like, "Very nice! Very nice house!"

I think the last time I played at Sweet Rhythm, it was really diverse, too. It was a great mixture of chairs and people! (laughter)

\section{Mainstream Embrace?}

There was all this buzz over the last couple of years that was basically collateral damage from Bombay Dreams. You know, we all got a certain amount of extra attention from the mainstream.

Yeah, we got a little play. 
But I saw it as short-lived. I think I was quoted in The New York Times saying that I'm never going to stop being South Asian, even after this flavor-of-the-week business wears off. So the choices we make have to be much more about long-term survival as artists.

Yeah. And our focus has been kind of different. I don't think we've ever tried to play to or cater to this South Asian American community. I think our focus has always been to reach as broad a community as possible, which I think is ultimately more important and more satisfying.

Yeah, really you want to reach people who like the music, and those could be any kind of people. They could like it for any kind of reason, but you don't want them to just like it for shallow reasons. That won't last.

Right. And there are also plenty of people who can relate to the story who are coming at it from different immigrant communities or different variations of the same story.

Well, that accounted for my initial association with Asian Improv - that there was some sort of parallel story. Although, quite distinct at the same time. The differences became clear as time went on.

So where do we go from here?

I guess we just keep experimenting, and keep collaborating, and keep maintaining this skepticism in the musical status quo.

(laughter) While remaining up-to-date all along. It was funny, there was some grant proposal, maybe it was NYSCA, and I was just going to cut and paste some words from a previous application, maybe from only 2 or 3 years ago, and none of it worked. It just all seemed so out of date.

The 90 s version of grant-writing?

In the most self-deprecating terms, it was like the soapbox had broken and I needed to build a new one. Not that it didn't apply, but that it had just evolved so much beyond these artist statements that I was writing before that I just had to rethink the whole thing.

Right. The whole idea of trying to avoid the pitfalls or negative stereotypes associated with Indian music is so '90s! At this point, in 2005, it's a different battle. In a way, those tropes have become so prevalent and pervasive, that...

That they're not even stereotypes anymore. 
The difference now is that so many people willfully reenact those stereotypes. And not only do they do that, but they're successful doing it. So then, who are you to say that they are stereotypes, or that there's something wrong with them?

Well, the next few years are going to be pretty interesting. One of the things we brushed on was the industry issue, like being this anomaly: what the hell am I gonna do with this guy? How am I gonna market this guy? I can't pigeonhole him and there's no precedent for him, so what the hell? So, in other words, they don't want to touch you with a ten-foot pole. It will be interesting to see how that shifts. It may only shift because we've busted our asses and to some extent maybe can't be ignored.

I actually wonder, though. If it shifts, it may not be for us. It may be that we've laid the groundwork for something else to happen to somebody else. And I actually tend to think that that's really what's going to happen.

Why?

Well, I think after we've been around long enough, it will start to seem like it's not new anymore. And I feel like we've probably reached enough prominence that we're influencing people who are a generation younger than we are. You know, people in our community who are twenty years younger than us, who are trying to play saxophone or piano, or anything. But when their time comes around, they'll have grown up dealing with the now.

With us as part of the fabric.

And also with contemporary American aesthetics. We grew up listening to classic rock and soul and pop, and early, early hip-hop. These kids were born after Public Enemy's first album, after De La Soul's first album. Long after Run-DMC's first album, definitely long after Purple Rain, The Police, the Pixies, whatever. So all the stuff that we grew up with is now old school. We are old school, here in our early thirties. So, it's not that I think we're going to get swept out of the picture, but I think that one of our main contributions will be complicating the picture enough to make it easier for subsequent generations to just be themselves and not worry about it - not even know that it was ever something to worry about.

At the same time, at least in our particular genre, the idea of anybody hitting it big is kind of done, anyway.

I think that has a lot to do with it. Like maybe people will hear about us, but if they do, they'll think, "Well, now I know what not to do, as much as I know what to do." Also, even as our work begins to feel more normative for some people, I think there's still a lot of resistance in general, in America. There's that whole series of hurdles that we have to get over; there's the jazz hurdle, there's the 
South Asian hurdle, there's the unpronounceable-name hurdle. In that sense we may always be seen as emerging artists. I find that when people are listening to music, they're not listening with their ears, even seasoned jazz listeners.

Well, those are the worst, actually.

Because they are subject to all these prejudicial influences that have nothing to do with what's being played, and they think they're right.

Those people want to put you in more boxes than anyone.

Well, that's also a generational thing. I mean, those people grew up seeing nobody like us, ever certainly not on the street; maybe they'd go to Indian restaurants once in a while. So now, having to deal with us as a fact, there's this kind of undercurrent of, "Who do you think you are?" And I don't know if we'll ever...

Get past that? Yeah. But l'm not sure anybody ever won everybody over, though. I'm sure there are plenty of people who, if they were still alive, would still be saying that of Charlie Parker.

\section{http://rudreshm.com}

\section{http://vijay-iyer.com}

